\title{
Residual Printing Solvents in Packaging Materials
}

\author{
Didier Louvier* and Eric Martine
}

\begin{abstract}
Analysis of residual printing solvents in packaging materials. The aim was to define an analytical method based on the static headspace gas chromatography (HS-GC) method with a mass spectrometric detector (MSD) to qualify and quantify residual printing solvents. The quantitations are compared for mono headspace extraction and multi headspace extraction (MHE).
\end{abstract}

Keywords: Mass spectrometry detection · Mono and multi (MHE) headspace extraction - Residual printing solvents in packaging materials . Static headspace gas chromatography - Thermodynamic equilibrium

\section{Introduction}

The identification and quantitation of residual printing solvents in packaging materials are very important for the material packaging suppliers, the printers and the packaging users of food and pharmaceutical products. As it is obvious that the inks are not in direct contact with the packed product, indirect contamination may occur through the external layers of the packaging materials during storage before transformation into packages. In this case, the solvents may present a toxicity risk or modify the organoleptic quality of the packed product.

Given the fact that there are numerous packaging materials and a large range of relevant solvents used in the printing and laminating process, we have tried to evaluate the global properties of solubility and diffusion of these solvents in packaging materials.

To do this, an analytical method must be able to:

- desorb the residual printing solvents,

- qualify the residual printing solvents,

- quantify the residual printing solvents.

\footnotetext{
${ }^{*}$ Correspondence: Prof. D. Louvier

Packaging Laboratory

University of Applied Sciences Vaud (EIVD)

Member of University of Applied Sciences West

Switzerland (HES-SO)

route de Cheseaux 1

$\mathrm{CH}-1400$ Yverdon-les-Bains

Tel.: + 41244232331

Fax: + 41244232331

E-Mail: didier.louvier@eivd.ch
}

Monitoring the limits of solvent content in packaging materials as selected by the users, requires a method that is applicable to a range of relevant solvents used in printing and laminating processes. According to current industrial practices, a list (see Table 1) of 28 solvents could be established.

\section{Experimental}

An analytical method based on static headspace gas chromatography (HS-GC) coupled with a mass spectrometer (MS) as detector (see Table 2) has been developed to:

Table 1. List of solvents

\begin{tabular}{llll} 
Solvents & CAS N & Solvents & CAS N \\
\hline $\begin{array}{l}\text { Cyclohexane } \\
\text { Methanol }\end{array}$ & $110-82-7$ & Vinyl acetate & $108-05-4$ \\
Ethanol & $67-56-1$ & Propyl acetate & $109-60-4$ \\
1-Propanol & $64-17-5$ & Isopropyl acetate & $108-21-4$ \\
2-Propanol & $71-23-8$ & Methoxy-2-ethyl acetate & $110-49-6$ \\
1-Butanol & $67-63-0$ & Ethoxy-2-ethyl acetate & $111-15-9$ \\
2-Butanol & $71-36-3$ & Methyl glycol & $109-86-4$ \\
Isobutanol & $15892-23-6$ & Ethyl glycol & $110-80-5$ \\
Ethanediol & $78-83-1$ & 1-Methoxypropan-2-ol & $107-98-2$ \\
Acetone & $107-21-1$ & 1-Ethoxypropan-2-ol & $1569-02-4$ \\
Methylethylketone & $67-64-1$ & m-Xylene & $108-38-3$ \\
Methylisobutylketone & $78-93-3$ & o-Xylene & $95-47-6$ \\
Cyclohexanone & $108-10-1$ & p-Xylene & $106-42-3$ \\
Ethyl acetate & $108-94-1$ & Toluene* & $108-88-3$ \\
\hline
\end{tabular}

*Toluene is still used in Asia, not in Europe
1. create an authorized solvents database (MSDATA) in printing ink,

2. propose an identification and quantitation method (HS-GC-MS) for the residual printing solvents in packaging materials,

3. compare the quantitation results obtained by mono and multi headspace extraction (MHE).

\section{Measuring Conditions and Analytical Method}

The samples were taken from a film roll in the centre of the web. A piece of $1 \mathrm{dm}^{2}$ of material was placed in a $20 \mathrm{ml}$ vial, which was then sealed. The sample was equili- 
brated with its gas phase at $85{ }^{\circ} \mathrm{C}$ for a period of $60 \mathrm{~min}$. After preliminary results, a preconditioning, before the equilibration, was realized in an oven at $85{ }^{\circ} \mathrm{C}$ for a defined period. The head space, HS, i.e. the gaseous phase, was then injected into a gas chromatograph with a mass spectrometric detector (Table 2).

The analysed materials are, e.g.:

- Surface print PET

- Surface print PP

- PET/internal print/PE/A1/PE(PE/EVA)

- Surface print paper/PE

\section{Results}

\section{Thermodynamic Equilibrium}

The thermodynamic equilibrium useful for the quantitation depends on:

- the chemical nature of the solvent,

- the printing process,

- the chemical nature of the packaging material,

- the interaction between solvent and packaging material,

and was reached after a preconditioning time from 1 to $24 \mathrm{~h}$ at $85{ }^{\circ} \mathrm{C}$.

For example, in case of the reverse printed sample $\mathrm{PET} /$ internal print/PE/ $\mathrm{Al} /$ $\mathrm{PE}$ (PE/EVA), the thermodynamic equilibrium required for the identified solvents is reached after at least a $12 \mathrm{~h}$ preconditioning period at $85^{\circ} \mathrm{C}$.

Fig. 1a shows the peak area in function of the preconditioning time for the solvents of major amount while Fig. 1b shows the minority solvents.

In both cases, the thermodynamic equilibrium is reached after $12 \mathrm{~h}$ preconditioning at $85{ }^{\circ} \mathrm{C}$ for this kind of multi-layer material.

\section{Mono Headspace Extraction in Function of the Thermodynamic Equilibrium}

When the thermodynamic equilibrium is not reached, the determined concentrations are much lower and some solvent may not be detected (Table 3).

\section{Mono-, Multi Headspace Extraction and Quantitation}

When the thermodynamic equilibrium is determined, it is possible to quantify the solvents either in mono extraction or in MHE. Under this condition the theory of MHE is verified, so Ln (Peak Area) is a linear function of the number of extraction steps (Fig. 2, Table 4).

For this material, the thermodynamic equilibrium at $85^{\circ} \mathrm{C}$ is reached after $3 \mathrm{~h}$ and the determined amounts for the two solvents are in the same range after $6 \mathrm{~h}$ of preconditioning.
Table 2. Apparatus and method

\begin{tabular}{|c|c|c|}
\hline Apparatus & Reference & Parameters \\
\hline $\begin{array}{l}\text { Static headspace auto } \\
\text { sampler }\end{array}$ & $\begin{array}{l}\text { HS 40XL, } \\
\text { Perkin Elmer }\end{array}$ & $\begin{array}{l}\text { Thermostatisation: } 60 \mathrm{~min} \text { at } 85^{\circ} \mathrm{C} \text {, } \\
\text { Injection: } 0.1 \mathrm{~min}\end{array}$ \\
\hline Gas chromatograph & $\begin{array}{l}\text { Auto sampler, } \\
\text { Perkin Elmer }\end{array}$ & $\begin{array}{l}5 \text { min at } 40^{\circ} \mathrm{C}, 5^{\circ} \mathrm{C} / \mathrm{min} \text { to } 120^{\circ} \mathrm{C} \\
\text { and } 10^{\circ} \mathrm{C} / \mathrm{min} \text { to } 240^{\circ} \mathrm{C} \\
\text { Injector: CAP at } 140^{\circ} \mathrm{C}\end{array}$ \\
\hline Column & $\begin{array}{l}\text { Supelcowax }{ }^{\mathrm{TM}}-10 \\
\text { capillary column }\end{array}$ & $\begin{array}{l}\text { PEG Stationary Phase, } 30 \mathrm{~m} \times 0.2 \mathrm{~mm} \\
\times 0.2 \mu \mathrm{m} \text { film thickness } \\
\text { Carrier gas: Helium } 100 \mathrm{kPa} \text { at } 25 \mathrm{~cm} / \mathrm{s}\end{array}$ \\
\hline Mass spectrometer & $\begin{array}{l}\text { TurboMass, } \\
\text { Perkin Elmer }\end{array}$ & $\begin{array}{l}\text { Masses: } 10-250 \text {; Interface: } 200^{\circ} \mathrm{C} \text {; } \\
\text { Source: } 180^{\circ} \mathrm{C}\end{array}$ \\
\hline
\end{tabular}

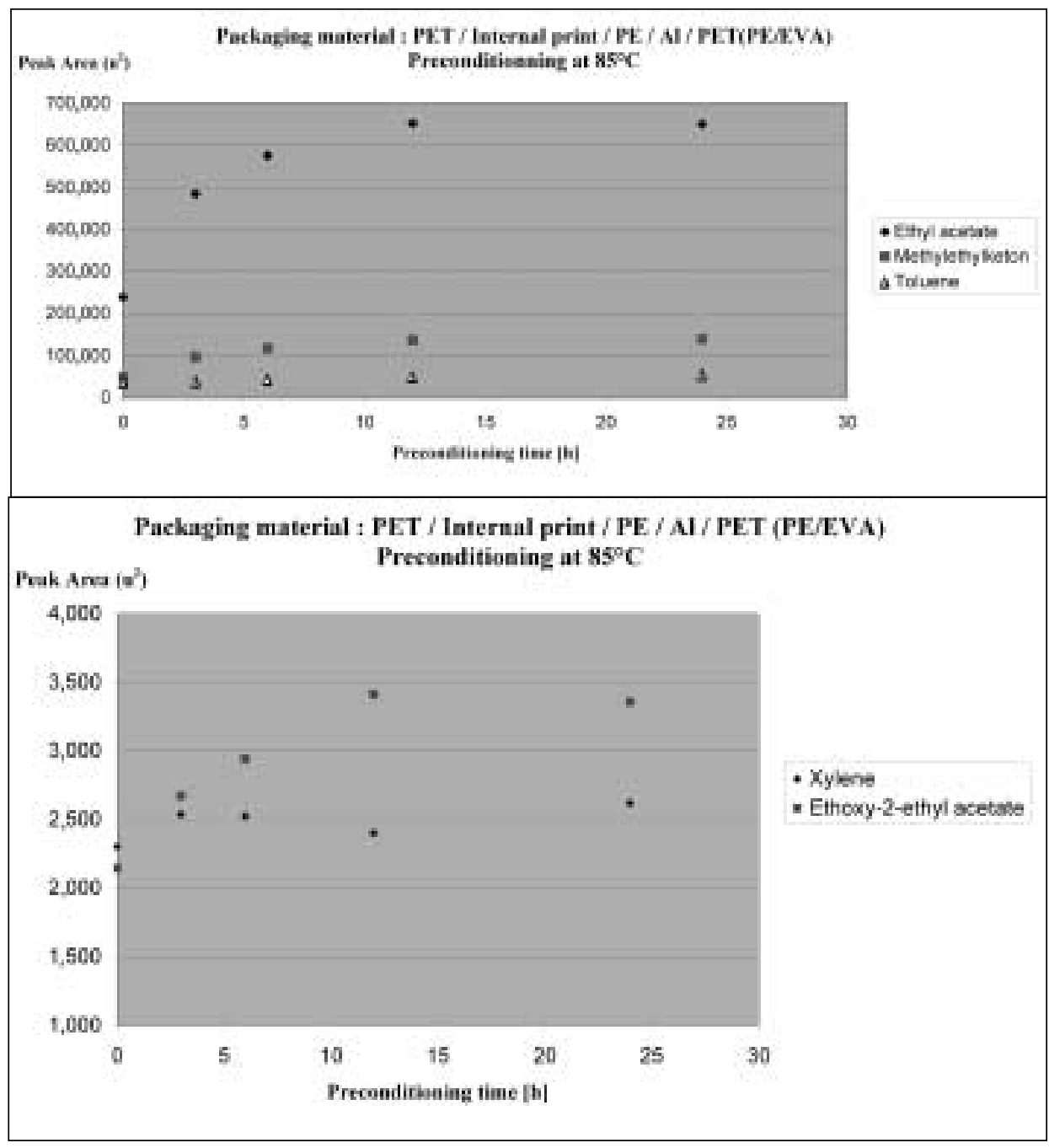

Fig. 1. a) Amount of residual solvents in function of preconditioning times at $85^{\circ} \mathrm{C}$. PET/Internal print/PE/AI/PE(PE/EVA). b) Amount of residual solvents in function of preconditioning times at $85^{\circ} \mathrm{C} . \mathrm{PET} /$ internal print/PE/Al/ PE(PE/EVA). 
Table 3. Comparison between concentrations when the thermodynamic equilibrium is not reached or is reached for three solvents in surface print PET film.

Note: Concentrations given are the amount of solvent per square meter of printed packaging material

\begin{tabular}{lccc} 
Solvents & $\begin{array}{l}\text { Thermodynamic equilibrium } \\
\text { not reached } \\
\text { Concentration }\left[\mathbf{m g} / \mathbf{m}^{2}\right]\end{array}$ & $\begin{array}{l}\text { Thermodynamic equilibrium } \\
\text { reached } \\
\text { Concentration }\left[\mathbf{m g} / \mathbf{m}^{2}\right]\end{array}$ & $\begin{array}{l}\Delta \mathbf{C} \\
{[\%]}\end{array}$ \\
\hline 1-Methoxypropan-2-ol & 1.45 & 1.69 & +17 \\
Ethyl acetate & 0.06 & 0.13 & +117 \\
Methanol & Not detectable & 0.10 & -
\end{tabular}

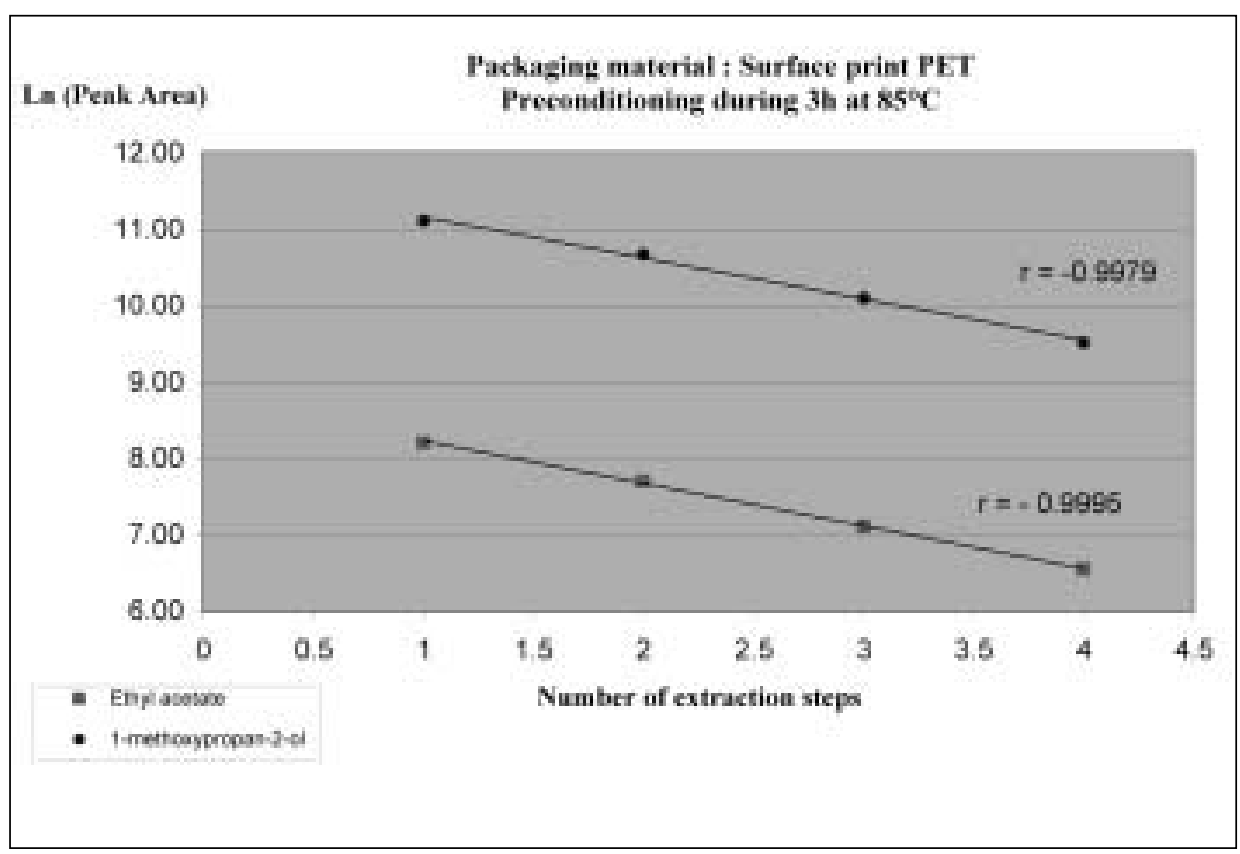

Fig. 2. Semi-log relationship between peak area and the number of extraction steps in MHE measurements of a sample of a surface print PET.

Table 4. Quantitation of residual printing solvent of surface print PET $\left[\mathrm{mg} / \mathrm{m}^{2}\right]$

\begin{tabular}{lccccc} 
Solvents & $\begin{array}{c}\text { Preconditioning } \\
\text { time [h] }\end{array}$ & $\begin{array}{c}\mathbf{C}_{1} \\
{\left[\mathbf{m g} / \mathbf{m}^{2}\right]}\end{array}$ & $\begin{array}{c}\mathbf{C}_{2} \\
{\left[\mathbf{m g} / \mathbf{m}^{2}\right]}\end{array}$ & $\begin{array}{c}\mathbf{C}_{3} \\
{\left[\mathbf{m g} / \mathbf{m}^{2}\right]}\end{array}$ & $\begin{array}{c}\mathbf{C}_{4} \\
{\left[\mathbf{m g} / \mathbf{m}^{2}\right]}\end{array}$ \\
\hline 1-Methoxypropan-2-ol & 3 & 1.65 & 1.38 & 1.61 & 1.64 \\
Ethyl acetate & 6 & 1.73 & 1.50 & 1.61 & 1.64 \\
& 3 & 0.11 & 0.10 & 0.11 & 0.11 \\
& 6 & 0.14 & 0.16 & 0.20 & 0.17
\end{tabular}

$\mathrm{C}_{1}$ : Concentration determined with the $1^{\text {st }}$ extraction $\mathrm{A}_{1}$-Mono Headspace Extraction

$\mathrm{C}_{2}$ : Concentration determined with the first two extractions by using the simplified MHE relation: $S_{A}=A_{1}^{2} /\left(A_{1}-A_{2}\right)$

$\mathrm{C}_{3}$ : Concentration determined with the first three extractions by using linear regression

$\mathrm{C}_{4}$ : Concentration determined with the four extractions by using linear regression:

$A_{1}$ : Peak area of the $1^{\text {st }}$ extraction

$A_{2}$ : Peak area of the $2^{\text {nd }}$ extraction

$\mathrm{S}_{\mathrm{A}}$ : Sum of the peak areas for the first two extractions

\section{Discussion}

For the analysis of any new packaging material, the following points must be addressed:

1. Whatever the structure of the packaging material, the thermodynamic equilibrium must be defined in order to be as close as possible to the real amount of residual printing solvents. To reach the thermodynamic equilibrium, a preconditioning time must be set. If the thermodynamic equilibrium is not reached, the error in the amount of solvent determined would be enormous. If the thermodynamic equilibrium is not reached, some solvents could not be detected at $85{ }^{\circ} \mathrm{C}$. To work either in Mono or in MHE, the thermodynamic equilibrium has to be reached.

2. Moreover, when MHE is applied, a minimum of three extraction steps has to be realized.

3. According to the above points, the MHE at this preconditioning time will allow the quantification and qualification of the residual printing solvents in a new packaging material.

4. In order to specify the parameters of the analytical method, the temperature and the time of the preconditioning in particular, it is important to know:

- how the material will be stored before use (time, temperature ...),

- what will be the conditions of use of the packaging material in its final configuration?

Bearing in mind that a printed packaging material must not be a solvent 'tank'.

Even though MHE could be too timeconsuming for routine analyses, the results show that the MHE HS-GC-MS method is well adapted for the quality control in residual printing solvents for packaging materials.

Received: April 23, 2002

[1] B. Kolb, 'Multiple Headspace Extraction - A Procedure for Eliminating the Influence of the Sample Matrix in Quantitative Headspace Gas Chromatography', Chromatographia 1982, 154(9), 587-594.

[2] B. Kolb, L.S. Ettre, 'Static Headspace-Gas Chromatography', Wiley-VCH, 1997.

[3] L. Spack. A. Collet, R. Buffat, 'Residual Solvents in Packaging Materials', Nestlé Research Center, 2000.

[4] B. Kolb, P. Pospisil, M. Auer, 'Quantitative Bestimmung von Restlösemitteln in bedruckten Verpackungsfolien nach dem Verfahren der Mehrfach-Gasextraktion', Perkin Elmer, 1981. 